\title{
Atypical depression: current perspectives
}

This article was published in the following Dove Press journal:

Neuropsychiatric Disease and Treatment

20 September 2017

Number of times this article has been viewed

\author{
Dorota Łojko' \\ Janusz K Rybakowski ${ }^{1,2}$ \\ 'Department of Adult Psychiatry, \\ ${ }^{2}$ Department of Child and Adolescent \\ Psychiatry, Poznan University of \\ Medical Sciences, Poznan, Poland
}

\begin{abstract}
The history and present status of the definition, prevalence, neurobiology, and treatment of atypical depression (AD) is presented. The concept of AD has evolved through the years, and currently, in Diagnostic and Statistical Manual of Mental Disorders (DSM), Fifth Edition, the specifier of depressive episode with atypical feature is present for both diagnostic groups, that is, depressive disorders and bipolar and related disorders. This specifier includes mood reactivity, hyperphagia, hypersomnia, leaden paralysis, and interpersonal rejection sensitivity. Prevalence rates of $\mathrm{AD}$ are variable, depending on the criteria, methodology, and settings. The results of epidemiological studies using DSM criteria suggest that $15 \%-29 \%$ of depressed patients have $\mathrm{AD}$, and the results of clinical studies point to a prevalence of $18 \%-36 \%$. A relationship of $\mathrm{AD}$ with bipolar depression, seasonal depression, and obesity has also been postulated. Pathogenic research has been mostly focused on distinguishing AD from melancholic depression. The differences have been found in biochemical studies in the areas of hypothalamic-pituitary-adrenal axis, inflammatory markers, and the leptin system, although the results obtained are frequently controversial. A number of findings concerning such differences have also been obtained using neuroimaging and neurophysiological and neuropsychological methods. An initial concept of $\mathrm{AD}$ as a preferentially monoamine oxidase inhibitor-responsive depression, although confirmed in some further studies, is of limited use nowadays. Currently, despite numerous drug trials, there are no comprehensive treatment guidelines for $\mathrm{AD}$. We finalize the article by describing the future research perspectives for the definition, neurobiology, and treatment. A better specification of diagnostic criteria and description of clinical picture, a genome-wide association study of $\mathrm{AD}$, and establishing updated treatment recommendations for this clinical phenomenon should be the priorities for the coming years.
\end{abstract}

Keywords: hypersomnia, hyperphagia, obesity, bipolar disorder, seasonal affective disorder

\section{Introduction}

Although first described in 1959, ${ }^{1}$ depression with atypical features (atypical depression, AD) appeared in the Diagnostic and Statistical Manual of Mental Disorders (DSM) as a specifier of major depression and dysthymia in 1994 (DSM-IV). ${ }^{2}$ Since the issues of $\mathrm{AD}$ have been accompanied by controversy, in this review, we discuss the history and the present status of such issues as definition, prevalence, neurobiology, and treatment of $\mathrm{AD}$. In the last part of the paper, we attempt to delineate future perspectives of this clinical phenomenon.

\section{Definition}

The first definition of AD as a preferentially monoamine oxidase inhibitor (MAOI)responsive depression was introduced by West and Dally in $1959 .{ }^{1}$ Prior to such description, the term "atypical depression" was used in $1948^{3}$ for describing depressed patients presenting with agitation, paranoid features, and perplexity, who responded well to electroconvulsive therapy (ECT). In DSM-III, the term was used for depression
Correspondence: Dorota Łojko Department of Adult Psychiatry, Poznan University of Medical Sciences, ul.Szpitalna 27/33, Poznan, Poland Email lojko@ump.edu.pl 
secondary to schizophrenia, for dysthymic disorder with long periods of well-being, and for brief depression (nonadjustment disorder). ${ }^{4}$

In 1982, Davidson et $\mathrm{al}^{5}$ proposed two types of $\mathrm{AD}$ : type $\mathrm{A}$, with predominant anxiety symptoms, and type $\mathrm{V}$, with vegetative symptoms, such as hyperphagia, weight gain, oversleeping, and increased sexual drive. ${ }^{5}$ Features shared by both subtypes included early onset, female predominance, outpatient predominance, mildness, and few suicide attempts. Type $\mathrm{V}$ was the one frequently seen in bipolar patients. ${ }^{6}$

In 1994, the DSM-IV introduced the criteria for "atypical features" as a modifier of major depression and dysthymia. ${ }^{2}$ Diagnosis of $\mathrm{AD}$ consists of criteria for depression in major depressive disorder (MDD), a major depressive episode of bipolar disorder, or dysthymia, together with the following specifiers of AD: significant mood reactivity (mood brightness in response to actual or potential positive events) and two or more of the following symptoms: significant weight gain, increase in appetite, hypersomnia, leaden paralysis, and a long-standing pattern of interpersonal rejection sensitivity that results in significant social or occupational impairment. In addition, the patient cannot meet the criteria for melancholic or catatonic depression. Surprisingly, no change in DSM- $5^{7}$ in 2013 was introduced, despite substantial remarks presented by some authors many years prior to the introduction of DSM-5.,

The definition and clinical picture of $\mathrm{AD}$ have raised a number of controversies. Researchers from Columbia University established the so-called Columbia criteria for AD as chronic, mild, non-melancholic unipolar depression, with mood reactivity. The significance of mood reactivity reflected the theory that mood non-reactivity was an essential symptom of "endogenomorphic depression". ${ }^{10,11}$ Also, the symptom named by Liebowitz et al ${ }^{12}$ as "leaden paralysis", alternatively defined as lethargy, anergia, or fatigue, was added to the description of AD. The Columbia group pointed out that $\mathrm{AD}$ patients, when compared to patients with melancholic depression, had a significantly earlier onset of the illness, much more chronic course of the illness, and less frequently family members with a recurrent and severe depressive illness, but more often family members who were chronically depressed. ${ }^{13}$

The New South Wales University group also defined AD as chronic, mild, non-endogenous (non-melancholic) unipolar depression, but indicated the predominance of anxiety symptoms over mood symptoms and the significance of interpersonal rejection. Parker et $\mathrm{al}^{14}$ argued that mood reactivity did not show specificity with any other four criterion symptoms and claimed that anxiety may be more specific and common in AD.

Other studies pointed out an equal probability of mood non-reactivity and mood reactivity with two other associated features of atypical mood. ${ }^{15,16}$ According to Thase ${ }^{9}$ and Angst et al, ${ }^{17}$ mood reactivity is not useful for the diagnosis of $\mathrm{AD}$ and should not be regarded as an obligatory symptom. As noticed by O'Keane et al, ${ }^{18}$ "it is puzzling that the most controversial symptom in the diagnosis of atypical depression is also the only obligatory one in DSM". On the basis of the differences in the results of treatment, ${ }^{19}$ biology, and family history, a suggestion was also presented by Stewart ${ }^{20}$ that depression with atypical features may include at least two types of disorders, one having an early onset and a very chronic illness course and the other with either a later onset or a less chronic course.

The concept that AD is related to bipolar disorder was put forward at the turn of the century. The Pittsburgh University group claimed that $\mathrm{AD}$ is a depressive state that can be observed in bipolar disorder and regarded the reversed vegetative symptoms and lethargy as signs of bipolar disorder. ${ }^{20}$ According to the bipolar spectrum concept, ${ }^{22} \mathrm{AD}$ shares features with bipolar II disorder or soft bipolar spectrum disorder. ${ }^{22-24}$ That idea was supported by the findings in a Polish cross-sectional study where among depressed patients a significantly higher frequency of atypical depressive symptoms (hypersomnia and hyperphagia) in bipolar than unipolar group was found. ${ }^{25}$ Also, in a national survey performed in the general population in the US, ${ }^{26}$ individuals with AD had significantly higher rates of bipolar I disorder than those without atypical feature. Patients with AD diagnosed with bipolar disorder differed from those with MDD: bipolar AD patients had more psychiatric comorbidities, younger age of onset, higher number of episodes, higher rates of family history of depression, earlyonset anxiety, and rejection sensitivity, and reported more often suicidal thoughts and suicide attempts. The authors concluded that

all those suggested that the characteristics of atypical depression, although common in both disorders, are even more accentuated in bipolar depression than in MDD with atypical features. ${ }^{26}$

Patients with AD have substantial comorbidity with a variety of anxiety disorders (eg, social phobia), eating disorders, and substance-related disorders, which may affect clinical outcomes. ${ }^{27}$ Some authors also suggest that AD may be misdiagnosed as personality disorders (borderline, 
histrionic, or avoidant). ${ }^{14,28}$ According to the review on AD by Silverstein and Angst ${ }^{29}$ which focused on comorbid disorders, disordered eating (including bingeing as well as intentional food restrictions), poor body image, pain, insomnia, and fatigue (separately from leaden paralysis) may actually reflect multiple manifestations of a single disorder.

We studied 91 pairs of patients, matched by age, gender, and diagnosis in which one member of the pair was within the normal weight range (body mass index $[\mathrm{BMI}] \leq 25$ ) and the other was either overweight or obese $(\mathrm{BMI}>25)$. There were 35 pairs with MDD, 27 with bipolar depression, and 29 with dysthymia. We found that all the symptoms of AD were significantly more pronounced in those depressed patients with a BMI $>25$ compared with depressed subjects with a normal weight. Among the diagnostic categories, symptoms of $\mathrm{AD}$ were significantly higher in patients with bipolar disorder compared with both MDD and dysthymia. ${ }^{30}$

Hypersomnia, hyperphagia, and loss of energy are also more likely to be reported in the so-called seasonal affective disorder (SAD). However, only $10 \%$ of AD patients reported a seasonal pattern of affective episodes, and the differences between $\mathrm{AD}$ and $\mathrm{SAD}$ in terms of symptoms suggest that they form separate subtypes of depression with an overlapping symptom picture. ${ }^{31,32}$
As AD may be a subtype of depression, one should mention the papers presenting negative results on symptom dimensions or subtypes of depression. According to van Loo et al, ${ }^{33}$ studies completed to date do not provide conclusive evidence of the existence of depressive symptom dimensions or symptomatic subtypes. Fifteen different subtypes were described in a meta-review of Harald and Gordon, ${ }^{34}$ with symptom-based melancholia, psychotic, and atypical subtypes, and also etiologically based and time-of-onsetbased subtypes. According to the authors, anxious subtype of depression and gender-based and treatment-based subtypes of depression were judged as too unspecific to qualify as a subtype of depression. They pointed out that there is a substantial overlap across the five categories and 15 subtypes of depression. The history of the definition of $\mathrm{AD}$ is depicted in Table 1.

\section{Prevalence of AD}

Since the first attempt to define AD, many studies on its prevalence have been performed. Variable definitions, as well as differences between studies in cutoff scores for rating the features, have greatly influenced the results of epidemiological studies. Prevalence rates of atypical subtype may depend on the criteria, method, and settings of the study.

Table I The history of the description/definition of atypical depression (AD)

\begin{tabular}{|c|c|}
\hline Date, author(s) & Description/definition of AD \\
\hline 1948, Huston and & Depressed patients presenting with agitation, paranoid features, and perplexity, who respond well to \\
\hline Locher $^{3}$ & electroconvulsive therapy \\
\hline 1959, West and Dally' & $\begin{array}{l}\text { Depression responsive to monoamine oxidase inhibitors; lack of features commonly seen in endogenous depression } \\
\text { such as guilt, early waking, weight loss, an improved mood at night, and a good response to electroconvulsive therapy }\end{array}$ \\
\hline 1980, DSM-III & $\begin{array}{l}\text { Depression secondary to schizophrenia, dysthymic disorder with long periods of well-being, and brief depression } \\
\text { (non-adjustment disorder) }\end{array}$ \\
\hline 1982, Davidson et $\mathrm{al}^{5}$ & $\begin{array}{l}\text { Depression responsive to monoamine oxidase inhibitors. Types of AD: type A, with predominant anxiety symptoms, } \\
\text { and type } V \text {, with vegetative symptoms, such as increased appetite, weight gain, oversleeping, and increased sexual } \\
\text { drive (both types share such features as early onset, female predominance, outpatient predominance, mild symptoms, } \\
\text { and few suicide attempts) }\end{array}$ \\
\hline $\begin{array}{l}\text { 1984, The Columbia } \\
\text { criteria of } A D^{10-12}\end{array}$ & $\begin{array}{l}\text { Chronic, mild, non-melancholic unipolar depression, with mood reactivity; "leaden paralysis”, alternatively defined } \\
\text { as lethargy, anergia, or fatigue; AD patients, compared to patients with melancholic depression, have a significantly } \\
\text { earlier onset of the illness, much more chronic course of the illness, and less frequently family members with a } \\
\text { recurrent and severe depressive illness, but more often family members who were chronically depressed }\end{array}$ \\
\hline 1994, DSM-IV² & $\begin{array}{l}\text { Diagnosis of AD consists of criteria for depression in major depressive disorder, a major depressive episode of } \\
\text { bipolar disorder, or dysthymia, together with the specifiers of AD: significant mood reactivity (mood brightness in } \\
\text { response to actual or potential positive events) and two or more of the following symptoms: significant weight gain, } \\
\text { increase in appetite, hypersomnia, leaden paralysis, and a long-standing pattern of interpersonal rejection sensitivity } \\
\text { that results in significant social or occupational impairment. The patient cannot meet the criteria for melancholic or } \\
\text { catatonic depression }\end{array}$ \\
\hline $2013, \mathrm{DSM}-5^{7}$ & As above \\
\hline 2002, The New South & Chronic, mild, non-endogenous (non-melancholic) unipolar depression; predominance of anxiety symptoms over \\
\hline Wales University Group ${ }^{14}$ & $\begin{array}{l}\text { mood symptoms and the significance of interpersonal rejection; mood reactivity does not show specificity with any } \\
\text { other four criteria symptoms; anxiety may be more specific and common in AD }\end{array}$ \\
\hline 2007, The Pittsburgh & Depressive state that can be observed in bipolar disorder. Reversed vegetative symptoms and lethargy are regarded \\
\hline University Group ${ }^{22-24}$ & as signs of bipolar disorder; AD shares features with bipolar II disorder or soft bipolar spectrum disorder \\
\hline
\end{tabular}

Abbreviation: DSM, Diagnostic and Statistical Manual of Mental Disorders. 
Most depressed patients present mixed features of $\mathrm{AD}$ and melancholic depression, with only $25 \%-30 \%$ presenting with pure melancholic features and 15\%-30\% with pure atypical features. ${ }^{35}$

In a national survey in the US in early 1990s, 36\%-39\% of patients with depression had hypersomnia and overeating, identified as AD. ${ }^{36}$ Those AD patients differed from those with non-AD in terms of demographic features, psychiatric comorbidities, and drug abuse history. Results from a national epidemiological survey of the US population performed 10 years later ${ }^{26}$ showed $10.2 \%$ prevalence of lifetime depression with atypical features, while the prevalence of depression without atypical features was 6.3\%. Among individuals with atypical features, $43.5 \%$ had only hypersomnia, $23.8 \%$ only hyperphagia, and $32.5 \%$ showed both symptoms. According to the results of that survey, patients with bipolar I (but not II) disorder were more likely to display the atypical features than those with major depression.

According to Thase's ${ }^{21}$ review presented in 2007, the results of epidemiological studies using DSM-IV criteria suggest that 15\%-29\% of depressed patients have AD which translates to a 1 -year prevalence of $1 \%-4 \%$. This concurs with clinical studies yielding a prevalence of $\mathrm{AD}$ as $18 \%-36 \%$.

The percentage of AD found in the GENDEP (Genomebased Therapeutic Drugs for Depression study was 7.4. ${ }^{37}$ In the outpatients studied in the STAR*D (Sequenced Treatment Alternatives to Relieve Depression) trial, 18.1\% had depression with atypical features. ${ }^{38}$ In a community sample of young adults (Zurich cohort study), the cumulative incidence rates of various types of depression were as follows: melancholia or AD (in one group), 4.1\%; pure melancholia, 7.1\%; pure AD, 3.5\%; and unspecified depression, $8.2 \% .^{17}$

Gili et al ${ }^{39}$ studied clinical patterns and treatment outcomes in 1,455 depressed patients. In this group, $16.2 \%$ met the DSM-IV criteria for melancholic depression and $24.7 \%$ for AD. Compared with melancholic depression, atypical depressive patients were less severely depressed, had fewer depressive episodes, and showed higher rates of comorbid anxiety disorders and substance abuse, and higher rates of remission.

A consistent finding across all studies is that AD is associated with younger age of onset of depression, female preponderance (two to three times more likely in women than in men), occurrence of anxiety, and a history of bipolar II disorder. ${ }^{8,9,26,40}$ Also, family history of depression, both unipolar and bipolar, has been found to be more frequent in
AD patients. ${ }^{26,41}$ It was even postulated by Stewart ${ }^{20}$ to use the diagnosis of depression with atypical features only in the case of patients who report a very early onset (before 20 years of age) and a very chronic course of illness since onset (no spontaneous 2-month period of well-being), and to add those criteria to DSM.

In some studies, it has been noted that diagnostic stability over time, in relation to a given subtype of depression, is present only in about $22 \%-29 \%$ of cases. ${ }^{17,42}$ More patients experience fluctuations between melancholic and atypical episodes than continuing with either type consistently over time. Also, observation in the Zurich cohort study (between age 26 and 41) showed that one-third of patients with depression with reversed vegetative syndromes had manifested in the longitudinal course also a typical vegetative syndrome (loss of appetite/weight and insomnia). ${ }^{24}$

\section{Neurobiology and neuropsychology of AD}

A number of neurobiological and neuropsychological studies on the pathogenesis of $\mathrm{AD}$ have been performed. They produced interesting results; however, when analyzed, most findings showed an overlap between atypical and non-atypical groups. The family studies have provided some support for the validity of the atypical subtype of major depression. In the twin study of depressive subtypes, higher concordance rates for the atypical subtype in monozygotic (odds ratio $[\mathrm{OR}]=5.4)$ than dizygotic $(\mathrm{OR}=1.0)$ twins were noted. ${ }^{43}$ The community-based family study of the mood disorder spectrum performed by Lamers et $\mathrm{al}^{44}$ showed greater diagnostic specificity of the familial aggregation of the atypical than the melancholic subtype of major depression.

Changes in the hypothalamic-pituitary-adrenal (HPA) axis are frequently used to suggest the opposing biological features of melancholic depression vs AD. This concept was presented by Gold and Chrousos. ${ }^{35}$ Relatively hyperactive HPA axis leading to the symptoms of melancholia and a relatively hypoactive stress response leading to the symptoms of AD have been postulated. They implicate the corticotropinreleasing hormone (CRH) hypersecretion and hyposecretion in the syndromal pattern of melancholic depression and AD, respectively. ${ }^{35}$ A meta-analysis of studies on the HPA axis conducted by Stetler and Miller ${ }^{45}$ has identified a pattern of relative hypocortisolemia in AD compared to the melancholic spectrum of depressive disorders, but findings of other authors are inconsistent. O'Keane et $\mathrm{al}^{18}$ suggest that there is a possibility of a "switch" in the regulation of the HPA system from CRH to arginine vasopressin resulting in 
an altered homeostasis within the HPA system which may explain the changing profile of depression over time.

The inflammatory theory of depression is another concept for a biological basis of depressive psychopathology. Elevated concentrations of pro-inflammatory cytokines, such as interleukin (IL)-6, tumor necrosis factor-alpha (TNF- $\alpha$ ), and C-reactive protein (CRP), are among the most consistent findings in patients with depression. ${ }^{46}$ In patients with $\mathrm{AD}$ vs non-AD and healthy controls, inflammation appears to be significantly greater in those with $\mathrm{AD}$ and $\mathrm{AD}$ has different pro-inflammatory cytokine patterns compared to melancholic depression. IL-6 levels were elevated in patients suffering from $\mathrm{AD}$ but not in patients with typical depression, compared to normal controls. ${ }^{47}$ However, in the paper of Dunjic-Kostic et al, ${ }^{48}$ IL-6 was higher in patients with melancholic type of depression compared to healthy controls, and TNF- $\alpha$ was lower in melancholic depression and AD patients compared to healthy controls. AD has been linked to decreased IL-4 and increased IL-2 compared to individuals without atypical features in one study, ${ }^{49}$ while another study reported decreased IL-2 in AD compared with controls. ${ }^{50}$ Patients with AD had higher CRP levels than those with no depression or with non-AD. ${ }^{51}$ As an elevated CRP level has been found to predict coronary artery disease, and increased cytokines are related to metabolic syndrome, ${ }^{47} \mathrm{AD}$ patients seem to be at an increased risk of developing those somatic conditions. In a 6-year longitudinal study of clinical course of depression, ${ }^{52}$ the atypical subtype group had the highest BMI and the highest prevalence of metabolic syndrome. The correlation of IL-6 in AD was found to be significant with glycated hemoglobin, insulin, waist circumference, BMI, and CRP. ${ }^{47}$

Another theory points to the leptin dysregulation (resistance) as the underlying mechanism connecting obesity and depression. ${ }^{53}$ Leptin is an adipose-derived hormone involved in the regulation of mood and emotions with presumably antidepressant-like efficacy. ${ }^{53}$ In a group of patients with depression, leptin concentration was strongly associated with clinical symptoms of $\mathrm{AD}$, such as hyperphagia, increased weight, and leaden paralysis. ${ }^{56}$ Our study demonstrated a higher prevalence of AD symptoms in obese patients compared to non-obese depressed patients. ${ }^{30}$

The neuroimaging studies of depression have shown a variety of abnormalities, particularly in the hippocampus, but also in the white matter. However, the relationship between the severity of symptoms and the hippocampus volume, as well as white matter integrity, is unclear. This may be related to the heterogeneity of depression. ${ }^{55}$ In some studies, an attempt has been made to examine the relationship between structural or functional changes in the brain and depression subtypes. Studies comparing the hippocampus volume between depressed patients with atypical features and those with melancholic features found no significant differences. ${ }^{56,57}$ Recently, Ota et $\mathrm{al}^{58}$ examined differences in white matter integrity assessed with diffusion tensor imaging in $\mathrm{AD}$, melancholic depression, and control group. The results suggest that patients with depression had reduced white matter integrity in some regions; however, there was no major difference between $\mathrm{AD}$ and melancholic depression.

Fountoulakis et $\mathrm{al}^{59}$ compared brain perfusion by using single-photon emission computerized tomography in patients with $\mathrm{AD}$ and melancholic depression and in control subjects. When compared with other depressed groups, AD patients had increased frontal, temporal, and parietal perfusion coupled with decreased occipital perfusion. Relative to controls, patients with $\mathrm{AD}$ also had increased right frontal perfusion, whereas those with melancholia and undifferentiated depression had decreased perfusion in the majority of non-occipital regions. As summarized by Thase, ${ }^{9}$ increased right hemispheric processing was reported in $\mathrm{AD}$ patients, compared with both non-AD and healthy controls. Patients with $\mathrm{AD}$ showed increased right parietal processing, whereas those with typical depression demonstrated increased left parietal processing. ${ }^{59}$ In a review presented by Lee and Kim, ${ }^{60}$ the results of studies suggest a pattern where melancholia and undifferentiated depression had similar abnormal brain perfusion that differed from those with $\mathrm{AD}$. This was also confirmed in a study assessing chimeric faces as a measure of perceptual asymmetry where AD patients indicated relatively increased right parietal processing. ${ }^{61}$

Differences between $\mathrm{AD}$ and melancholic depression have been demonstrated in neurophysiological studies. In a study of the assessment of the visual evoked potentials using electroencephalogram (EEG) after a visual stimulus, N80 and P100 latencies were significantly shorter in $\mathrm{AD}$ and longer in melancholic patients. ${ }^{62}$ In another study, the loudness dependence of auditory evoked potentials (LDAEP) recorded in the EEG was stronger in $\mathrm{AD}$ patients than in those with non-AD. Since LDAEP has been proposed as a biomarker of serotonin activity, the results suggest a relatively deficient serotonergic activity in patients with $\mathrm{AD}$, which may be connected with their mood reactivity. ${ }^{63}$ Recently, Veronezi et al, ${ }^{64}$ using the transcranial magnetic stimulation method, found increased motor cortical facilitation and decreased inhibition in $\mathrm{AD}$ compared with other depression subtypes. This was related 
to gamma-aminobutyric acid A-receptor and glutamatergic activity in the motor cortex.

Recently, a systematic literature review on neuropsychological studies in melancholic depression and AD was published. ${ }^{65}$ The authors compared the results of cognitive tests in melancholic and non-melancholic type of depression (NMD). ${ }^{65}$ According to the review, melancholic patients have poorer performance compared to NMD patients when it comes to tasks involving verbal and visual memory, executive function, sustained attention and span, as well as psychomotor speed. In the authors' opinion, verbal fluency tests and psychomotor speed tasks seem to be suitable tools for differentiating AD from melancholic depression, since melancholic patients performed worse and showed more extensive and greater impairments than NMD patients. ${ }^{65}$

A psychological hypothesis about AD takes into account the personality and temperament ${ }^{40}$ to distinguish patients with AD from those with typical depression. It was proposed that pathological sensitivity to perceived interpersonal rejection (resulting in social or occupational impairment) forms the main feature of AD. The personal pattern of rejection sensitivity is always accompanied by a variety of dysregulated emotional (exceeded anxiety) and self-consolatory problems (oversleeping and overeating). ${ }^{14}$ In this concept, the spectrum of atypical depressive disorder was suggested, viewing it as psychological or reactive in origin.

\section{Treatment}

The concept of AD emerged from the clinical observations of West and Dally in 1959. ${ }^{1}$ They noted that some depressed patients did not benefit from imipramine and ECT, the treatments usually effective for what they called "typical" depression, but achieved remarkable benefits when treated with iproniazid, the original MAOI. Therefore, the first recommendation on how to treat $\mathrm{AD}$ stemmed from the definition of $\mathrm{AD}$ as "a preferentially monoamine oxidase inhibitor-responsive state". Superiority of the MAOI phenelzine over imipramine in depressed patients, meeting the Liebowitz et al ${ }^{12}$ criteria of AD, was demonstrated in studies performed at the turn of 1980-1990s. ${ }^{66-68}$ The study of Stewart et $\mathrm{al}^{69}$ in patients with major depression showed a robust therapeutic effect of imipramine in patients without, but not with, atypical features.

Since 1990s, studies have also been performed comparing moclobemide, a reversible inhibitor of monoamine oxidase, with other antidepressant drugs in the treatment of AD. As far as selective serotonin reuptake inhibitors (SSRIs) are concerned, Lonnqvist et $\mathrm{al}^{70}$ showed a better effect of moclobemide than fluoxetine. However, in another study, a lack of differences in efficacy was found between moclobemide and sertraline. ${ }^{71}$ A comparison of moclobemide and a tricyclic antidepressant, clomipramine, within a project of the DUAG (Danish University Antidepressant Group) Study, showed a better effect of moclobemide than clomipramine in patients with atypical vegetative symptoms, while the reverse was true for patients suffering from typical depression. ${ }^{72}$

Following initial skepticism as to the efficacy of ECT in $\mathrm{AD},{ }^{1}$ no controlled studies of ECT in this condition have been performed. In 2008, Husain et $\mathrm{al}^{73}$ examined the outcomes of patients with MDD divided into the typical $(n=453)$ and the atypical $(n=36)$ group who were treated with acute bilateral ECT. Remission was obtained in $67.1 \%$ of typical depressed patients and in $80.6 \%$ of atypical ones, and the latter group was 2.6 times more likely to remit than the typical group after adjustment for age, psychosis, gender, and depression severity. Therefore, in the light of modern ECT, these early observations of West and Dally seem unconfirmed.

In 2006, a meta-analysis was published for the pharmacological treatment of depression with atypical features. Only eight publications met the criteria for a double-blind, controlled condition and an operational diagnosis of $\mathrm{AD}$, according to DSM. For the comparison of MAOI (including reversible ones) and tricyclic antidepressants, an effect size was 0.27 , suggesting a better efficacy of the former, while for MAOI and SSRI, such an effect was negligible (0.02), indicating a lack of differences in efficacy. ${ }^{74}$

However, nowadays, MAOIs are not widely used, and the treatment guidelines for AD are lacking. The results of newer studies have not produced any clear indications in this respect. Comparing with SSRI, Papakostas et al ${ }^{75}$ showed better efficacy of bupropion in improving hypersomnia and fatigue, elements of AD. Another study found that depressed patients with atypical features are less likely to remit with citalopram than those without atypical features. ${ }^{11}$ In the GENDEP study, there was no indication that AD may respond better to SSRI than to tricyclic antidepressants as a similar efficacy of escitalopram and nortriptyline was observed. ${ }^{37} \mathrm{Pae}$ et $\mathrm{al}^{76}$ in a post hoc analysis of five short-term trials with selegiline (selective MAOI type B) showed equal efficacy of this drug in patients with atypical and non-atypical subtype of depression.

Recently, the results of the iSPOT-D (International Study to Predict Optimized Treatment in Depression), including patients treated with escitalopram, sertraline, or venlafaxine, were reported. Three subtypes of patients were 
delineated: patients with melancholic, atypical (according to DSM criteria), and anxious depression. Thirty-nine percentage of patients exhibited a pure-form subtype, $36 \%$ more than one subtype, and $25 \%$ could not be classified as any of the subtype groups. Symptom reduction and likelihood of remission did not differ significantly between subtype groups. The authors of the study concluded that subtypes of depression may be of minimal value in antidepressant selection. ${ }^{77}$

Since symptoms like overeating and oversleeping, as well as "lethargy" (fatigue), are characteristic of SAD, an attempt was made to use light therapy for $\mathrm{AD}$, but the results were negative. ${ }^{78}$ More promising outcomes were obtained with exercise where hypersomnia and increased BMI had been associated with better response. Rethorst et $\mathrm{al}^{79}$ studied this procedure in depressed patients, and the results showed that patients with $\mathrm{AD}$ had better treatment response to exercise.

Psychotherapy, especially cognitive behavioral therapy (CBT), has been widely used in the treatment of depression, including AD. The efficacy of CBT in AD was demonstrated in a pilot study ${ }^{80}$ as well as in subsequent trials. ${ }^{81-83}$ In one of them, CBT treatment was found to be equal to the treatment with MAOI, phenelzine. ${ }^{81}$ Recently, Cuijpers et $\mathrm{al}^{84}$ performed a meta-analysis comparing $\mathrm{AD}$ and melancholic depression as a predictor of the therapeutic outcome of CBT and did not find any indication that either of these types can be a significant outcome moderator. They also found that these two types are not predictors to antidepressant treatment. Fournier et $\mathrm{al}^{85}$ point to a different change in specific depressive symptoms during a 16-week antidepressant (paroxetine) or CBT course of treatment. In their study, both treatments reduced cognitive and suicide symptoms; however, cognitive therapy reduced the atypical-vegetative symptoms more than medications, which suggests its usefulness in AD.

\section{Perspectives}

Depression is one of the most prevalent mental disorders, affecting some 121 million people worldwide. It increases the risk of suicide by 20 times and is among the leading causes of disability. According to the World Health Organization (WHO) data, by the year 2020, depression will be the second most common cause of disease and premature death worldwide. ${ }^{86}$ Identifying the atypical subtype of depression in terms of clinical and biological features would give patients a chance for personalized treatment. ${ }^{87}$ Therefore, studies should be directed at clarifying more issues such as diagnosis, neurobiology, and treatment, described in this article.

Although in 1982 Davidson et $\mathrm{al}^{5}$ claimed that "atypical depression is poorly defined", a recent review of Stewart et $\mathrm{al}^{8}$ argues for this clinical phenomenon as a valid entity. Better specification of diagnostic criteria and description of the clinical picture of $\mathrm{AD}$ taking into account the age of onset and the course would be required. Also, AD should have a proper place in the ICD-11. Further research on the neurobiology of AD is also needed, for example, the genome-wide association study. New pathogenic findings may broaden the biological characteristics of $\mathrm{AD}$ which may pave the way to a more specific treatment.

Guidelines for the treatment of AD taking into account the experiences gathered so far should be introduced in not too distant future. The algorithm for using appropriate antidepressants should be created. As the associations demonstrated between $\mathrm{AD}$ and bipolar depression may have therapeutic consequences and no pharmacological trials addressing this issue have been performed so far, we propose that, in each AD patient, a test for bipolarity should be performed (eg, by means of the Mood Disorder Questionnaire ${ }^{88}$ or Hypomania Checklist-32 scale ${ }^{89}$ ). In the event of a positive result, an attempt to use a drug with antidepressant and mood-stabilizing properties such as lithium, lamotrigine, quetiapine, or lurasidone can be made. Also, because patients with atypical features of depression become obese more frequently ${ }^{90}$ and have a resistance to leptin, ${ }^{54}$ drugs which do not influence appetite and body mass should be taken into account.

After nearly 60 years of existence in contemporary psychiatry, AD still remains an intriguing clinical phenomenon where a lot of research should be done for its better understanding and management.

\section{Disclosure}

The authors report no conflicts of interest in this work.

\section{References}

1. West ED, Dally PJ. Effects of iproniazid in depressive syndromes. Br Med J. 1959;1(5136):1491-1494.

2. American Psychiatric Association. Diagnostic and Statistical Manual of Mental Disorders. 4th ed. Washington, DC: American Psychiatric Association; 1994.

3. Huston PE, Locher LM. Manic-depressive psychosis; course when treated and untreated with electric shock. Arch Neurol Psychiatry. 1948; 60(1):37-48.

4. American Psychiatric Association. Diagnostic and Statistical Manual of Mental Disorders: DSM-III. Washington, DC: American Psychiatric Association; 1980.

5. Davidson JR, Miller RD, Turnbull CD, Sullivan JL. Atypical depression. Arch Gen Psychiatry. 1982;39(5):527-534.

6. Davidson JR, Thase ME. A history of the concept of atypical depression. J Clin Psychiatry. 2007;68(2):e03.

7. American Psychiatric Association. Diagnostic and Statistical Manual of Mental Disorders (DSM-5), Fifth Edition. Washington, DC: American Psychiatric Association; 2013. 
8. Stewart JW, McGrath PJ, Quitkin FM, Klein DF. DSM-IV depression with atypical features: is it valid? Neuropsychopharmacology. 2009; 34(13):2625-2632.

9. Thase ME. Atypical depression: useful concept, but it's time to revise the DSM-IV criteria. Neuropsychopharmacology. 2009;34(13): 2633-2641.

10. Quitkin FM, McGrath PJ, Stewart JW, Klein DF. A reappraisal of atypical depression. Am J Psychiatry. 2003;160(4):798-800.

11. Stewart JW, McGrath PJ, Fava M, et al. Do atypical features affect outcome in depressed outpatients treated with citalopram? Int $J$ Neuropsychopharmacol. 2010;13(1):15-30.

12. Liebowitz MR, Quitkin FM, Stewart JW, et al. Phenelzine v imipramine in atypical depression. A preliminary report. Arch Gen Psychiatry. 1984;41(7):669-677.

13. Stewart JW, McGrath PJ, Rabkin JG, Quitkin FM. Atypical depression. A valid clinical entity? Psychiatr Clin North Am. 1993;16(3): 479-495.

14. Parker G, Roy K, Mitchell P, Wilhelm K, Malhi G, Hadzi-Pavlovic D. Atypical depression: a reappraisal. Am J Psychiatry. 2002;159(9): 1470-1479.

15. Henkel V, Mergl R, Coyne JC, et al. Depression with atypical features in a sample of primary care outpatients: prevalence, specific characteristics and consequences. J Affect Disord. 2004;83(2-3):237-242.

16. Posternak MA, Zimmerman M. Partial validation of the atypical features subtype of major depressive disorder. Arch Gen Psychiatry. 2002; 59(1):70-76.

17. Angst J, Gamma A, Benazzi F, Ajdacic V, Rössler W. Melancholia and atypical depression in the Zurich study: epidemiology, clinical characteristics, course, comorbidity and personality. Acta Psychiatr Scand Suppl. 2007;(433):72-84.

18. O'Keane V, Frodl T, Dinan TG. A review of atypical depression in relation to the course of depression and changes in HPA axis organization. Psychoneuroendocrinology. 2012;37(10):1589-1599.

19. Stewart JW, Bruder GE, McGrath PJ, Quitkin FM. Do age of onset and course of illness define biologically distinct groups within atypical depression? J Abnorm Psychol. 2003;112(2):253-262.

20. Stewart J. Atypical depression: history and future. Psychiatr Ann. 2014; 44(12):557-562.

21. Thase ME. Recognition and diagnosis of atypical depression. $J$ Clin Psychiatry. 2007;68 Suppl 8:11-16.

22. Benazzi F. Depression with DSM-IV atypical features: a marker for bipolar II disorder. Eur Arch Psychiatry Clin Neurosci. 2000;250(1): 53-55.

23. Benazzi F. Atypical bipolar II depression compared with atypical unipolar depression and nonatypical bipolar II depression. Psychopathology. 2000;33(2):100-102.

24. Angst J, Gamma A, Benazzi F, et al. Atypical depressive syndromes in varying definitions. Eur Arch Psychiatry Clin Neurosci. 2006; 256(1):44-54.

25. Rybakowski JK, Suwalska A, Lojko D, Rymaszewska J, Kiejna A. Types of depression more frequent in bipolar than in unipolar affective illness: results of the Polish DEP-BI study. Psychopathology. 2007;40(3):153-158.

26. Blanco C, Vesga-López O, Stewart JW, Liu SM, Grant BF, Hasin DS. Epidemiology of major depression with atypical features: results from the National Epidemiologic Survey on Alcohol and Related Conditions (NESARC). J Clin Psychiatry. 2012;73(2):224-232.

27. Pae CU, Tharwani H, Marks DM, Masand PS, Patkar AA. Atypical depression: a comprehensive review. CNS Drugs. 2009;23(12): 1023-1037.

28. Perugi G, Fornaro M, Akiskal HS. Are atypical depression, borderline personality disorder and bipolar II disorder overlapping manifestations of a common cyclothymic diathesis? World Psychiatry. 2011; 10(1):45-51.

29. Silverstein B, Angst J. Evidence for broadening criteria for atypical depression which may define a reactive depressive disorder. Psychiatry J. 2015;2015:575931.
30. Łojko D, Buzuk G, Owecki M, Ruchala M, Rybakowski JK. Atypical features in depression: association with obesity and bipolar disorder. J Affect Disord. 2015;185:76-80.

31. Tam EM, Lam RW, Robertson HA, Stewart JN, Yatham LN, Zis AP. Atypical depressive symptoms in seasonal and non-seasonal mood disorders. J Affect Disord. 1997;44(1):39-44.

32. Juruena MF, Cleare AJ. Superposição entre depressão atípica, doença afetiva sazonal e síndrome da fadiga crônica [Overlap between atypical depression, seasonal affective disorder and chronic fatigue syndrome]. Rev Bras Psiquiatr. 2007;29 Suppl 1:S19-S26. Portuguese [with English abstract].

33. van Loo HM, de Jonge P, Romeijn JW, Kessler RC, Schoevers RA. Data-driven subtypes of major depressive disorder: a systematic review. BMC Med. 2012;10:156.

34. Harald B, Gordon P. Meta-review of depressive subtyping models. J Affect Disord. 2012;139(2):126-140.

35. Gold PW, Chrousos GP. Organization of the stress system and its dysregulation in melancholic and atypical depression: high vs low CRH/NE states. Mol Psychiatry. 2002;7(3):254-275.

36. Matza LS, Revicki DA, Davidson JR, Stewart JW. Depression with atypical features in the National Comorbidity Survey: classification, description, and consequences. Arch Gen Psychiatry. 2003;60(8):817-826.

37. Uher R, Dernovsek MZ, Mors O, et al. Melancholic, atypical and anxious depression subtypes and outcome of treatment with escitalopram and nortriptyline. $J$ Affect Disord. 2011;132(1-2):112-120.

38. Novick JS, Stewart JW, Wisniewski SR, et al; STAR*D investigators. Clinical and demographic features of atypical depression in outpatients with major depressive disorder: preliminary findings from STAR*D. J Clin Psychiatry. 2005;66(8):1002-1011.

39. Gili M, Roca M, Armengol S, Asensio D, Garcia-Campayo J, Parker G. Clinical patterns and treatment outcome in patients with melancholic, atypical and non-melancholic depressions. PLoS One. 2012;7(10):e48200.

40. Parker GB. Atypical depression: a valid subtype? J Clin Psychiatry. 2007;68 Suppl 3:18-22.

41. Akiskal HS, Benazzi F. Atypical depression: a variant of bipolar II or a bridge between unipolar and bipolar II? J Affect Disord. 2005; 84(2-3):209-217.

42. Melartin T, LeskeläU, RytsäläH, SokeroP,Lestelä-Mielonen P, IsometsäE. Co-morbidity and stability of melancholic features in DSM-IV major depressive disorder. Psychol Med. 2004;34(8):1443-1452.

43. Kendler KS, Eaves LJ, Walters EE, Neale MC, Heath AC, Kessler RC. The identification and validation of distinct depressive syndromes in a population-based sample of female twins. Arch Gen Psychiatry. 1996;53(5):391-399.

44. Lamers F, Cui L, Hickie IB, et al. Familial aggregation and heritability of the melancholic and atypical subtypes of depression. J Affect Disord. 2016;204:241-246.

45. Stetler C, Miller GE. Depression and hypothalamic-pituitary-adrenal activation: a quantitative summary of four decades of research. Psychosom Med. 2011;73(2):114-126.

46. Dowlati Y, Herrmann N, Swardfager W, et al. A meta-analysis of cytokines in major depression. Biol Psychiatry. 2010;67(5):446-457.

47. Rudolf S, Greggersen W, Kahl KG, Huppe M, Schweiger U. Elevated IL-6 levels in patients with atypical depression but not in patients with typical depression. Psychiatry Res. 2014;217(1-2):34-38.

48. Dunjic-Kostic B, Ivkovic M, Radonjic NV, et al. Melancholic and atypical major depression-connection between cytokines, psychopathology and treatment. Prog Neuropsychopharmacol Biol Psychiatry. 2013;43:1-6.

49. Yoon HK, Kim YK, Lee HJ, Kwon DY, Kim L. Role of cytokines in atypical depression. Nord J Psychiatry. 2012;66(3):183-188.

50. Anisman H, Ravindran AV, Griffiths J, Merali Z. Endocrine and cytokine correlates of major depression and dysthymia with typical or atypical features. Mol Psychiatry. 1999;4(2):182-188.

51. Hickman RJ, Khambaty T, Stewart JC. C-reactive protein is elevated in atypical but not nonatypical depression: data from the National Health and Nutrition Examination survey (NHANES) 1999-2004. J Behav Med. 2014;37(4):621-629. 
52. Lamers F, Beekman AT, van Hemert AM, Schoevers RA, Penninx BW. Six-year longitudinal course and outcomes of subtypes of depression. Br J Psychiatry. 2016;208(1):62-68.

53. Lu XY. The leptin hypothesis of depression: a potential link between mood disorders and obesity? Curr Opin Pharmacol. 2007;7(6): 648-652.

54. Milaneschi Y, Lamers F, Bot M, Drent ML, Penninx BW. Leptin dysregulation is specifically associated with major depression with atypical features: evidence for a mechanism connecting obesity and depression. Biol Psychiatry. 2017;81(9):807-814.

55. Cole J, Chaddock CA, Farmer AE, et al. White matter abnormalities and illness severity in major depressive disorder. Br J Psychiatry. 2012;201(1):33-39.

56. Greenberg DL, Payne ME, MacFall JR, Steffens DC, Krishnan RR. Hippocampal volumes and depression subtypes. Psychiatry Res. 2008; 163(2):126-132.

57. Rusch BD, Abercrombie HC, Oakes TR, Schaefer SM, Davidson RJ. Hippocampal morphometry in depressed patients and control subjects: relations to anxiety symptoms. Biol Psychiatry. 2001;50(12): 960-964.

58. Ota M, Noda T, Sato N, et al. White matter abnormalities in major depressive disorder with melancholic and atypical features: a diffusion tensor imaging study. Psychiatry Clin Neurosci. 2015;69(6) 360-368.

59. Fountoulakis KN, Iacovides A, Gerasimou G, et al. The relationship of regional cerebral blood flow with subtypes of major depression. Prog Neuropsychopharmacol Biol Psychiatry. 2004;28(3): 537-546.

60. Lee HY, Kim YK. Different mechanisms between melancholic and atypical depression. In: Major Depressive Disorder - Cognitive and Neurobiological Mechanisms. InTech; 2015.

61. Bruder GE, Stewart JW, McGrath PJ, Ma GJ, Wexler BE, Quitkin FM. Atypical depression: enhanced right hemispheric dominance for perceiving emotional chimeric faces. J Abnorm Psychol. 2002;111(3): 446-454.

62. Fotiou F, Fountoulakis KN, Iacovides A, Kaprinis G. Pattern-reversed visual evoked potentials in subtypes of major depression. Psychiatry Res. 2003;118(3):259-271.

63. Lee SH, Park YC, Yoon S, Kim JI, Hahn SW. Clinical implications of loudness dependence of auditory evoked potentials in patients with atypical depression. Prog Neuropsychopharmacol Biol Psychiatry. 2014;54:7-12.

64. Veronezi BP, Moffa AH, Carvalho AF, et al. Evidence for increased motor cortical facilitation and decreased inhibition in atypical depression. Acta Psychiatr Scand Suppl. 2016;134(2):172-182.

65. Bosaipo NB, Foss MP, Young AH, Juruena MF. Neuropsychological changes in melancholic and atypical depression: a systematic review. Neurosci Biobehav Rev. 2017;73:309-325.

66. Liebowitz MR, Quitkin FM, Stewart JW, et al. Antidepressant specificity in atypical depression. Arch Gen Psychiatry. 1988;45(2):129-137.

67. Quitkin FM, Stewart JW, McGrath PJ, et al. Phenelzine versus imipramine in the treatment of probable atypical depression: defining syndrome boundaries of selective MAOI responders. Am J Psychiatry. 1988;145(3):306-311.

68. Quitkin FM, McGrath PJ, Stewart JW, et al. Atypical depression, panic attacks, and response to imipramine and phenelzine. A replication. Arch Gen Psychiatry. 1990;47(10):935-941.

69. Stewart JW, Garfinkel R, Nunes EV, Donovan S, Klein DF. Atypical features and treatment response in the National Institute of Mental Health Treatment of Depression Collaborative Research Program. J Clin Psychopharmacol. 1998;18(6):429-434.

70. Lonnqvist J, Sihvo S, Syvälahti E, Kiviruusu O. Moclobemide and fluoxetine in atypical depression: a double-blind trial. J Affect Disord. 1994;32(3):169-177.

71. Søgaard J, Lane R, Latimer P, et al. A 12-week study comparing moclobemide and sertraline in the treatment of outpatients with atypical depression. J Psychopharmacol. 1999;13(4):406-414.
72. Bech P, Stage KB, Larsen JK, Vestergaard P, Gram LF; DUAG. The predictive validity of atypical neurovegetative depressive symptoms identified by the first principal component in the DUAG trial of moclobemide versus clomipramine. J Affect Disord. 2012;140(3):253-259.

73. Husain MM, McClintock SM, Rush AJ, et al. The efficacy of acute electroconvulsive therapy in atypical depression. J Clin Psychiatry. 2008;69(3):406-411.

74. Henkel V, Mergl R, Allgaier AK, Kohnen R, Möller HJ, Hegerl U. Treatment of depression with atypical features: a meta-analytic approach. Psychiatry Res. 2006;141(1):89-101.

75. Papakostas GI, Nutt DJ, Hallett LA, Tucker VL, Krishen A, Fava M. Resolution of sleepiness and fatigue in major depressive disorder: a comparison of bupropion and the selective serotonin reuptake inhibitors. Biol Psychiatry. 2006;60(12):1350-1355.

76. Pae CU, Patkar AA, Jang S, Portland KB, Jung S, Nelson JC. Efficacy and safety of selegiline transdermal system (STS) for the atypical subtype of major depressive disorder: pooled analysis of 5 short-term, placebo-controlled trials. CNS Spectr. 2014;19(4):324-329.

77. Arnow BA, Blasey C, Williams LM, et al. Depression subtypes in predicting antidepressant response: a report from the iSPOT-D trial. Am J Psychiatry. 2015;172(8):743-750.

78. Stewart JW, Quitkin FM, Terman M, Terman JS. Is seasonal affective disorder a variant of atypical depression? Differential response to light therapy. Psychiatry Res. 1990;33(2):121-128.

79. Rethorst CD, Tu J, Carmody TJ, Greer TL, Trivedi MH. Atypical depressive symptoms as a predictor of treatment response to exercise in Major Depressive Disorder. J Affect Disord. 2016;200:156-158.

80. Mercier MA, Stewart JW, Quitkin FM. A pilot sequential study of cognitive therapy and pharmacotherapy of atypical depression. J Clin Psychiatry. 1992;53(5):166-170.

81. Jarrett RB, Schaffer M, McIntire D, Witt-Browder A, Kraft D, Risser RC. Treatment of atypical depression with cognitive therapy or phenelzine: a double-blind, placebo-controlled trial. Arch Gen Psychiatry. 1999;56(5):431-437.

82. Jarrett RB, Kraft D, Schaffer M, et al. Reducing relapse in depressed outpatients with atypical features: a pilot study. Psychother Psychosom. 2000;69(5):232-239.

83. Henkel V, Mergl R, Allgaier AK, et al. Treatment of atypical depression: post-hoc analysis of a randomized controlled study testing the efficacy of sertraline and cognitive behavioural therapy in mildly depressed outpatients. Eur Psychiatry. 2010;25(8):491-498.

84. Cuijpers P, Weitz E, Lamers F, et al. Melancholic and atypical depression as predictor and moderator of outcome in cognitive behavior therapy and pharmacotherapy for adult depression. Depress Anxiety. 2017;34(3):246-256.

85. Fournier JC, DeRubeis RJ, Hollon SD, Gallop R, Shelton RC, Amsterdam JD. Differential change in specific depressive symptoms during antidepressant medication or cognitive therapy. Behav Res Ther. 2013;51(7):392-398.

86. Murray CJ, Lopez AD. Global mortality, disability, and the contribution of risk factors: Global Burden of Disease Study. Lancet. 1997; 349(9063):1436-1442.

87. Korte SM, Prins J, Krajnc AM, et al. The many different faces of major depression: it is time for personalized medicine. Eur J Pharmacol. 2015; 753:88-104

88. Hirschfeld RM, Williams JB, Spitzer RL, et al. Development and validation of a screening instrument for bipolar spectrum disorder: the Mood Disorder Questionnaire. Am J Psychiatry. 2000;157(11): 1873-1875.

89. Angst J, Adolfsson R, Benazzi F, et al. The HCL-32: towards a selfassessment tool for hypomanic symptoms in outpatients. $J$ Affect Disord. 2005;88(2):217-233.

90. Buzuk G, Łojko D, Owecki M, Ruchała M, Rybakowski J. Depression with atypical features in various kinds of affective disorders. Psychiatr Pol. 2016;50(4):827-838. 


\section{Publish your work in this journal}

Neuropsychiatric Disease and Treatment is an international, peerreviewed journal of clinical therapeutics and pharmacology focusing on concise rapid reporting of clinical or pre-clinical studies on a range of neuropsychiatric and neurological disorders. This journal is indexed on PubMed Central, the 'PsycINFO' database and CAS,

and is the official journal of The International Neuropsychiatric Association (INA). The manuscript management system is completely online and includes a very quick and fair peer-review system, which is all easy to use. Visit http://www.dovepress.com/testimonials.php to read real quotes from published authors.

Submit your manuscript here: http://www.dovepress.com/neuropsychiatric-disease-and-treatment-journal 